\title{
INVENTARISASI DAN KARAKTERISASI KUMBANG ANTENA PANJANG (CERAMBYCIDAE) DI HUTAN TALANG PEMATANG PUDU PROVINSI RIAU
}

\author{
Ennie Chahyadi ${ }^{1)}$, Fahri $^{2)}$, Dilla Asrizalni ${ }^{3)}$ \\ ${ }^{1), 3)}$ Jurusan Biologi, Universitas Riau, ${ }^{2}$ Jurusan Biologi, Universitas Tadulako. \\ email $^{l)}$ : chahyadi.ennie@gmail.com \\ email $^{2)}$ :fahribadjib@gmail.com \\ email $^{3)}$ :dilla.asrizalni@student.unri.ac.id
}

\begin{abstract}
ABSTRAK: Kumbang longhorn yang dikenal dengan nama kumbang cerambycid merupakan kumbang yang memiliki peran sangat penting dalam proses pembusukan yang berguna bagi keseimbangan ekosistem hutan. Keanekaragaman kumbang ini masih belum banyak diketahui dan dipelajari di Indonesia, terutama di Provinsi Riau. Sedangkan provinsi ini memiliki heterogenitas vegetasi yang tinggi yang merupakan habitat dan sumber makanan bagi kumbang antena panjang. Penelitian ini bertujuan untuk menginventarisasi dan mengkarakterisasi kumbang longhorn di hutan Talang Pematang Pudu Provinsi Riau. Metode yang digunakan adalah menggunakan perangkap Arthrocarpus. Kumbang dikumpulkan pada pukul 15.00 wib. Kemudian dilakukan pengawetan dan identifikasi karakter morfologi berdasarkan ciri kepala, dada dan perut. Hasil penelitian didapatkan sebanyak 12 spesies kumbang longhorn, dengan genera yang terdiri dari Sybra, Pterolophia, dan Epepeotes dari Subfamili Lamiinae. Jumlah individu yang diperoleh sebanyak 110 kumbang. Ciri-ciri kumbang longhorn yang dapat membedakan jenis kumbang terdapat pada ciri-ciri antena, elytra, skutelum dan pronotum.
\end{abstract}

\section{Kata Kunci : Kumbang longhorn, Cerambycid, Riau}

ABSTRACT:The longhorn beetle known as the Cerambycid beetle, is a beetle that has a very important role in the decomposition process which is useful for the balance of the forest ecosystem. The diversity of these beetles is still not widely known and studied in Indonesia, expectially in Riau Province. Meanwhile, the province has high vegetation heterogeneity which is a habitat and source of food for long antennae beetles. This study aims to inventory and characterize longhorn beetles in the Talang Pematang Pudu forest, Riau Province. The method used is using the Arthrocarpus trap. Beetles are collected at 15.00 wib. Then performed preservation and identification of morphological characters based on the characteristics of the head, thorax and abdomen. The results obtained as many as 12 species of longhorn beetles, with genera consisting of Sybra, Pterolophia, and Epepeotes from the Lamiinae Subfamily. The total number of individuals was obtained as many as 110 beetles. Characteristics of longhorn beetles that can distinguish between types of beetles are found in the characteristics of the antennae, elytra, skutelum and pronotum.

Key Word: longhorn beetles, Cerambycid, Riau

\section{PENDAHULUAN}

Kumbang antena panjang atau disebut juga dengan kumbang cerambicyd merupakan serangga dari
Famili Cerambycidae yang memiliki morfologi unik. Keunikan ini dilihat dari ukuran antena yang melebihi dari ukuran panjang tubuhnya. 
Sehingga kumbang tersebut merupakan kumbang yang terkenal dalam Ordo Coleoptera (Perveen 2017). Selain itu keberadaan kumbang antena panjang di suatu habitat hutan sangatlah penting. Hal ini terkait perannya yang membantu dalam proses dekomposisi yang berguna untuk keseimbangan ekosistem hutan (Dagobert et al. 2008; Raje et al. 2012). Proses tersebut dikarenakan larva kumbang antena panjang yang hidup dengan cara mengebor bagian batang tumbuhan berkayu, yang cenderung lebih menyukai batang pohon yang sudah lapuk atau kering (Noerdjito 2005).

Keanekaragaman kumbang antena panjang di Indonesia baru diketahui sebanyak 26 ribu jenis. Jumlah tersebut masih sangat sedikit dan hanya diketahui baru dari beberapa provinsi di Indonesia, seperti dari hutan Provinsi Jambi (Fahri 2013), hutan di Polokarto Jawa Tengah (Sataral 2015), hutan Halimum salak Jawa Barat (Putri 2015) dan perkebunan di Sulawesi Tengah (Rahmat et al. 2019). Jika dibandingkan dengan banyaknya hutan yang ada di Indonesia, dengan keanekaragaman vegetasi yang tinggi, tentunya akan ditemukan jenis kumbang antena panjang yang lebih beranekaragam lagi. Sehingga sangat penting dan menarik untuk terus menggali informasi tentang jenisjenis kumbang antena panjang yang ada di Indonesia.

Salah satunya di Provinsi Riau, belum ada informasi tentang keanekaragaman jenis kumbang antena panjang apa saja yang ada di Provinsi tersebut. Provinsi Riau terkenal dengan banyaknya tipe hutan yang kaya akan heterogenitas vegetasi yang tinggi. Salah satunya seperti pada hutan Talang Pematang Pudu di Kabupaten Bengkalis. Hutan ini terdiri dari berbagai macam jenis vegetasi seperti pohon akasia, gaharu, kempas, paku-pakuan, karet, kempayang, seminai, dan masih banyak lagi (Komunikasi Pribadi 2020). Sebagian besar merupakan habitat dan sumber makanan yang sangat disukai oleh kumbang antena panjang, baik pada fase dewasa maupun larva. Sehingga berpotensi untuk menemukan kumbang antena panjang di lokasi tersebut.

Oleh karena itu, sangat perlu melakukan inventarisasi jenis-jenis kumbang antena panjang apa saja yang ada di hutan Talang Pematang Pudu. Kemudian mengetahui dan mempelajari karakter-karakter morfologi setiap jenis kumbang antena panjang yang diperoleh dari lokasi tersebut. Informasi pada penelitian ini diharapkan dapat melengkapi data kumbang antena panjang di Indonesia, khususnya di Provinsi Riau.

\section{METODE PENELITIAN}

Lokasi penelitian yaitu di Hutan Talang Desa Pematang Pudu Kecamatan Mandau Kabupaten Bengkalis Provinsi Riau (N $00^{\circ}$ 94'02.18, E $102^{0}$ 02'00.58). Penelitian dilakukan pada bulan Juni-September tahun 2020. Identifikasi dan analisis data dilakukan di Laboratorium Zoologi dan Unit Fotomikrografi Jurusan Biologi FMIPA Universitas Riau. Metode penelitian dimulai dari koleksi sampel kumbang, pengawetan, identifikasi, dokumentasi, hingga analisis data.

\section{Koleksi Sampel Kumbang}

Koleksi sampel menggunakan metode Artocarpus trap (Noerdjito 2008). Perangkap ini menggunakan 
umpan daun nangka yang bertujuan agar senyawa yang dikeluarkan beruba odor atau bau dapat memikat kumbang antena panjang (Hanks et al. 2007). Jumlah perangkap sebanyak 16 perangkap, dengan jarak pemasangan perangkap setiap $50 \mathrm{~m}$ pada jalur transek. Lokasi pengambilan sampel seluas 100x16m. Koleksi sampel dilakukan sebanyak lima kali dengan rentang waktu pengambilan sampel berjarak tiga hari (hari ke-4, 7, 10, 13, 16). Koleksi dilakukan pada sore hari pukul 15.00 wib. Pengambilan sampel dengan mengoleksi kumbang yang jatuh pada penadah kain putih berukuran 1x1 m, setelah menggoyang atau memukul (beating) batang pohon yang telah diberi perangkap. Kemudian kumbang dimasukkan ke dalam killing bottle, dicatat identitas dan jumlah individunya (Fahri 2013).

\section{Pengawetan Sampel Kumbang}

Kumbang di bawa ke laboratorium untuk dilakukan pengawetan dan dibuat insektarium. Proses ini terdiri dari tahap pinning atau penusukan bagian torak dengan menggunakan jarum serangga. Namun jika ukuran tubuh kumbang kecil, maka menggunakan kertas segitiga (point). Setelah itu dilanjutkan ke tahapan labelling atau penulisan identitas kumbang. Pada tahap ini menggunakan kertas concord dan balok pinning (pinning block). Tahapan selanjutnya adalah proses pengeringan, dilakukan sekitar tiga hari hingga satu minggu disesuaikan dengan ukuran tubuh kumbang. Pengeringan menggunakan oven dengan kisaran suhu sebesar $45{ }^{\circ} \mathrm{C}$. Kemudian selanjutnya kumbang disimpan di dalam kotak koleksi yang sudah diberikan kapur barus agar terhindar dari serangga lain dan jamur (Makihara et al. 2002).

\section{Identifikasi dan Dokumentasi Kumbang}

Karakter morfologi yang digunakan dalam identifikasi meliputi bagian tubuh kepala, torkas, abdomen. Total karakter yang diamati sebanyak 20 karakter. Identifikasi berdasarkan Samuelson (1965), Makihara et al. (2002), Makihara \& Noerdjito (2004), Heffern (2013) dan Sataral (2015 \& 2017). Dokumentasi juga dilakukan untuk membandingkan tiap karakter pada individu dan jenis kumbang antena panjang. Pengamatan dan foto juga menggunakan mikroskop merk Olympus type $\mathrm{Cx} 41$ dan kamera Canon 1300D.

\section{Analisis Data}

Data disajikan dalam bentuk gambar dan tabel secara deskriptif. Data menyajikan jumlah jenis dan individu kemudian karakter morfologi kumbang antena panjang.

\section{HASIL DAN PEMBAHASAN}

\section{Jumlah Individu dan Jenis Kumbang Antena Panjang}

Kumbang antena panjang yang berhasil diperoleh sebanyak 12 jenis dan 110 individu. Kumbang yang ditemukan teridiri dari satu Subfamili yaitu Lamiinae dengan tiga tribe yaitu Apomecynini, Pteropliini dan Monochamini. Jumlah jenis kumbang antena panjang yang paling banyak ditemukan pada genus Pterolophia dari Pteropliini (Tabel 1).

Kumbang antena panjang Subfamili Lamiinae merupakan jenis kumbang antena panjang yang paling banyak ditemukan disetiap habitat. Hal ini karena kumbang tersebut memiliki banyak jenis makanan termasuk pemakan daun dan batang (Duffy 2012). Kumbang Lamiinae 
memiliki jumlah jenis yang paling banyak daripada subfamili lainnya, yaitu sekitar 20.000 jenis (Haks 1999; Noerdjito 2009 \& 2010; Noerdjito et al. 2011; Slipinski \& Escalona 2013; Xuanbi et al. 2020).
Selain itu, kumbang subfamili tersebut aktif pada siang hari, sehingga lebih mudah ditemukan keberadaannya (Noerdjito 2008).

Tabel 1. Jumlah jenis dan individu kumbang antena panjang

\begin{tabular}{clc}
\hline No & \multicolumn{1}{c}{ Subfamili/ Tribe/ Jenis } & Jumlah Individu \\
\hline & Subfamili Lamiinae : & \\
\hline I & Tribe Apmecynini & 8 \\
\hline 1 & Sybra cetrifera pascoe & 1 \\
\hline 2 & Sybra umbratica pascoe & 6 \\
\hline 3 & Sybra psaudalternans breuning & \\
\hline & & 1 \\
\hline II & Tribe Pteropliini & 6 \\
\hline 4 & Pterolophia crassipes & 1 \\
\hline 5 & Pterolophia devittata & 3 \\
\hline 6 & Pterolophia melanura & 75 \\
\hline 7 & Pterolophia propinqua & 2 \\
\hline 8 & Pterolophia uniformis & 2 \\
\hline 9 & Pterolophia sp1 & 1 \\
\hline 10 & Pterolophia sp2 & \\
\hline 11 & Pterolophia sp 3 & 4 \\
\hline & & $\mathbf{1 1 0}$ \\
\hline III & Tribe Monochamini & $\mathbf{1 2}$ \\
\hline 12 & Epepeotes luscus & \\
\hline & & \\
\hline & Total jumlah individu & \\
\hline & Total jumlah jenis & \\
\hline
\end{tabular}

Pada Tabel 1 di atas menunjukkan bahwa jenis kumbang antena panjang jenis Pterolophia uniformis memiliki jumlah yang paling banyak yaitu 75 individu, lebih dari setengah jumlah total individu kumbang antena panjang yang diperoleh pada hutan Talang. Jenis kumbang tersebut bersifat polypafagus, yang berarti memiliki sumber makanan lebih dari satu tumbuhan inang, sehingga perkembang biakan dari jenis kumbang ini juga lebih cepat. Selain itu, jenis kumbang antena panjang tersebut memiliki ukuran tubuh yang kecil. Sehingga mudah untuk beradaptasi terhadap kondisi habitatnya. Kumbang antena panjang yang memiliki ukuran tubuh yang lebih kecil memiliki larva yang dapat hidup pada cabang atau ranting pohon yang juga berukuran kecil (Ohsawa 2004 \& 2010; Noerdjito 2012; Waqa-Sakiti et al. 2013; Sataral et al. 2017). Jenis kumbang ini banyak ditemukan hampir disemua perangkap. Diduga hampir seluruh vegetasi di hutan dapat menjadi habitat dan sumber pakannya. Kumbang antena panjang yang juga memiliki ukuran tubuh kecil yaitu pada jenis Sybra cetrifera pascoe, S. psaudalternans breuning dan P. devittata (Gambar 1). 
Karakteristik Kumbang Antena Panjang

Karakteristik kumbang antena panjang meliputi karakter dari kepala, toraks dan abdomen.

\section{Karakteristik Kepala}

Karakter pada kepala yang diamati adalah posisi kepala, tipe antena, dan apical carina. Tipe posisi kepala untuk semua jenis kumbang antena panjang, yaitu terdiri dari tipe prognat dan hipognat. Tipe posisi kepala hipognat adalah wajah menghadap ke bawah, sedangkan posisi prognat yaitu wajah kumbang yang menghadap kedepan. Sementara itu, untuk tipe antena semuanya memiliki antena tipa filiform. Sesuai dengan Makihara et al. (2002 \& 2004) menyatakan bahwa kumbang antena panjang subfamili Lamiinae memiliki tipe antena filiform dengan jumbai rambut pendek. Jumlah segmen antena untuk semua jenis kumbang antena panjang beragam. Menurut Sataral (2015), jumlah segmen antena merupakan karakter untuk tingkat jenis. Selain itu juga dapat menjadi karakter dalam membedakan kumbang antena panjang jantan dan betina. Umumnya kumbang antena panjang betina terdiri dari 11-12 segmen, sementara yang jalan jumlah segmennya melebihi ukuran panjang tubuhnya. Kemudian untuk karakter skapus pada antena, terdiri dari dua tipe yaitu ada dan tidak ada apical carina. Jenis yang memiliki apical carina pada kumbang antena panjang Pterolophia $s p$ dan P. crassipes, untuk jenis yang lainnya tidak memiliki apical carina.
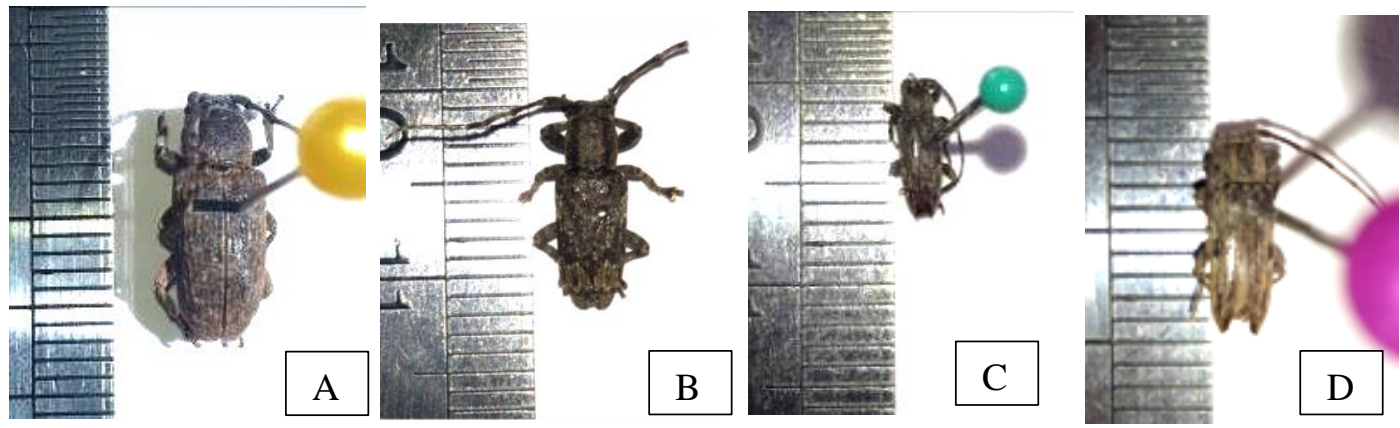

Gambar 1. Jenis-jenis kumbang antena panjang yang memiliki ukuran tubuh kecil. A. Pterolophia uniformis, B. Pterolophia devittata, C. Sybra cetrifera pascoe, D. Sybra psaudalternans breuning.

\section{Karakteristik Torak}

Karakter morfologi pada bagian dada yang diamati adalah elytra, pronotum, skutelum, ujung elytra dan warna elytra. Pada karakter elytra yang dilihat adalah bentuk dan warna. Warna elytra pada kumbang antena panjang yang ditemui adalah warna hitam, abu-abu, coklat dan coklat kehitaman. Sementara itu bentuk elytra terdiri dari dua bentuk yaitu oval dan silindris. Sesuai dengan ciri khas dari kumbang antena panjang pada Sugiarto el al. (2017 \& 2018). Bentuk ujung elytra bulat terdapat pada kumbang antena panjang Epepeotes luscus, Pterolophia Sp1, P. melanura, dan $P$. unifomis, selainnya memiliki bentuk elytra yang oval. Karakter berikutnya adalah jenis pronotum ada dan tidaknya memiliki lateral 
tubercle. Kumbang yang memiliki karakter tersebut hanya jenis $E$. luscus. Kemudian untuk karakter skutelum dibagi menjadi dua, yaitu skutelum yang berbentuk huruf $\mathrm{U}$ dan V. Kumbang dengan skutelum berbentuk huruf V yaitu $P$. crassipes.

\section{Karakteristik Abdomen}

Jumlah segmen perut pada kumbang antena panjang berkisar antara 9-10 segemen. Pada kumbang antena panjang jantan memiliki segmen abdomen sekitar 10 segmen, sementara pada betina sebanyak 9 segmen. Warna abdomen sebagian besar berwarna coklat, hitam dan coklat kehitaman. Karakter tersebut juga sesuai dengan Putri (2015).

\section{KESIMPULAN}

Kumbang antena panjang yang berhasil dikoleksi pada hutan Talang Pematang Putu Provinsi Riau yaitu sebanyak 12 jenis dan 110 individu. Kumbang tersebut dari Subfamili Lamiinae dan Tribe Apomecynini, Pteropliini dan Monochamini. Terdiri dari empat genus yaitu Sybra, Pterolophia, dan Epepeotes. Karakteristik morfologi kumbang dilihat pada bagian tubuh kepala, toraks dan abdomen. Para karakter yang paling dapat membedakan kumbang antena panjang adalah pada karakter tipe dan segmen antena, juga skapus. Kemudian selain itu juga karakter elytra, skutelum dan pronotum.

\section{DAFTAR PUSTAKA}

Dargobert KK, Klimaszewski J, Mamadaou D, Daouda D. 2008. Comparing beetle abundace and diversity value along a land use gradient in tropical Afroca (oume, Ivory coast).Jzool Stud, 47(4): 429437.
Duffy EAJ. 2012. Coleoptera (Cerambycidae). Copy Right Royal Entomological Society of London Vol V. Part 12. London.

Fahri. 2013. Keanekaragaman dan kelimpahan kumbang cerambycid (Coleoptera : Cerambycidae) pada empat tipe penggunaan lahan di Provinsi Jambi[Thesis] Institut Pertanian Bogor. Bogor (ID)

Haks LM. 1999. Influence of the Larval Host Plant on Reproductive Strategies of Cerambycidae Beetles. Annu Rev Entomol.483-505.

Heffern DJ. 2013. A Catalog and Bibliography of Longhorned Beetles from Borneo (Coleoptera: Cerambycidae, Disteniidae and Vesperidae) [bibliografi]. Electronic Version, 2013.1.

Makihara H, WA Noerdjito, Sugiarto. 2002. Longicorn Beetles from Gunung Halimun National Park, West Java, Indonesia from 19972002 (Coleoptera Distiniidae and Cerambycidae). Bull FFPRI. 1(3):189-223.

Makihara H, WA Noerdjito. 2004. Longicorn Beetles of Museum Zoologicum Bogoriense, Identified by Dr. E.F. Gilmour, 1963 (Coleoptera: Disteniidae and Cerambycidae). Bull FFPRI. 3(1): 49-98. 
Noerdjito, W. A., H, Makihara dan K, Matsumoto. 2005. Longicorn Beetle Fauna (Coleoptera: Cerambycidae) Colected from friendship Forest at sekaroh, Lombok.. Proc. Int. Workshop on the Landscape Level Rehabilitation of Degraded Tropical Forest, 22-23 Febuary, 2005, FFPRI, Tsukuba, Japan, pp: 55-64

Noerdjito WA. 2008. Struktur Komunitas Fauna Kumbang Antena Panjang (Coleoptera: Cerambycidae) di Kawasan Taman Nasional Gunung Cirenai. J Biol Indon.371384.

Noerdjito WA. 2009. Keragaman dan Distribusi Kumbang Sungut Panjang (Coleoptera: Cerambycidae) di Berbagai Tipe Habitat di Gunung Salak, Sisi Selatan Cidahu, Sukabumi Jawa Barat. LIPI:75-87.

Noerdjito WA. 2010. Arti Kebun Raya Bogor Bagi Kehidupan Kumbang Antena Panjang (Coloeoptera,

Cerambycidae). J Biol Indon. 289-292.

Noerdjito WA, Aswari P, Peggie D. 2011. Fauna Serangga Gunung Ciremai. LIPI Press. Bogor

Noerdjito WA. 2012. Dampak Kegiatan Manusia Terhadap Keragaman dan Pola Distribusi Kumbang Antena Panjang (Coleoptera: Cerambicidae) di Gunung salak Jawa Barat. $J$ Biol Indon. 57-69.

Ohsawa M. 2004. Species richness of Cerambycidae in larch plantations and natural broadleaved forests of the central mountainous region of Japan. Forest Ecol manag.189(13):375-385.

Doi:10.1016/j.foreco.2003.09 .007

Ohsawa M. 2010. Beetle families as indicators of coleopteran diversity in forests: A study using malaise traps in the central mountainous region of Japan. Insect Conserv. 14(5):479-484. doi: 10.1007/s10841-010-9276-4.

Perveen FK. 2017. Sistemati distribution of checklist of frist recorded longhom beetle (insecta: Coleoptera ) Fauna From Sheringal, Pakistan. Journal of Progressive Research in Biology 3:192199.

Putri E M. 2015. Keanekaragaman kumbang sungut panjang (Coleoptera: Cerambycidae) Di Kawasan Resort Salak2 Taman Nasional Gunung Halimun Salak (TNGHS). [Skripsi]. Universitas Islam Negeri Syarif Hidayatullah. Jakarta.

Rahmat , I Nengah Suwastika, Fahri.2019. Keanekaragaman Kumbang Cerambycid (Coleoptera: Cerambycidae) Pada Perkebunan kakao di tiga tipe habitat. Sulawesi Tengah. 
Raje KR, Abdel-Moniem HEM, Farlee L, Ferris VR, Holland JD. 2012. Abundance of Pest and Benign Cerambycidae Both Increase with Decreasing Forest Productivity. Agri Forest Entomol.165-169.

Samuelson GA. 1965. The Cerambycidae (Coleoptera.) of the Ryukyu Archipelago II, Lamiinae .Pacific Insects. 82-130.

Sataral M. 2015. Keanekaragaman dan Kelimpahan Kumbang Antena Panjang (Coleoptera:Cerambycidae) di Hutan Pendidikan Gunung Walat, Jawa Barat [Thesis]. Institut Pertanian Bogor. Bogor

Sataral M. 2017.Keanekaragaman Kumbang Antena Panjang (Coleoptera: Cerambycidae) pada Beberapa Perkebunan di polokarto, Jawa Tengah. Juornal of Natural Science. 90-99

Slipinski A, HE Escalona. 2013. Australian longhorn beetles (Coleoptera: Cerambycidae) volume 1 , introduction and subfamily Lamiinae. Wells A,editor. Canberra (AU) : CSIRO Publishing.

Sugiarto, Mersi L. 2017. Keanekaragaman Jenis Kumbang Berantena Panjang (Cerambycidae) di Perkebunan Kelapa Sawit PT NIKP Kecamatan Rantau Pulung Kabupaten Kutai
Timur. Jurnal Pertanian Terpadu. 5 (1).

Sugiarto, Chandradewana Boer, Djumali Mardi, Liris Lis Komara. 2018. Keanekaragaman Kumbang Sungut Panjang (Coleoptera: Cerambycidae) di Hutan Lindung Kalimantan Timur. 15(3)166-176.

Waqa-Sakiti H, Stewart A, Cizek L, Hodge S. 2013. Patterns of tree species usage by longhorn beetles (Coleoptera: Cerambycidae) in Fiji. Pacific Sci. 68(1):1-16.

Xuanbi W, Chen C, Lin M. 2020. Noteson the tribe petrognathini Blanchard, 1845 from china, with description of a new species from Yunnan (Coleoptera, Cerambycidae,

Lamiinae),Lianhuan South Road, Shanghai, 201100 China. 4732(3):453-460. 